\title{
Posttraumatic venous gas in the liver - a case report and review of the current literature
}

\author{
René Fahrner ${ }^{1 *}$, Falk Rauchfuss ${ }^{1}$, Hubert Scheuerlein ${ }^{1,2}$ and Utz Settmacher ${ }^{1}$
}

\begin{abstract}
Background: There are numerous causes of hepatic gas formation that range from serious pathologies to incidental findings, including mesenteric infarction, liver abscess, inflammatory bowel disease or minimally invasive hepatic interventions.
\end{abstract}

Case presentation: We report a case of a 50-year-old man who was admitted to the emergency room after a car accident. The clinical examination and further diagnostics revealed a craniocerebral injury with a fracture of the skull, concomitant soft tissue lesions and subarachnoidal bleeding. Furthermore, a blunt thoracic trauma with hemopneumothorax due to rib fractures was treated with a chest tube. No obvious abdominal pathology was seen. While in the operating theatre for the surgical revision of the cranial soft tissue lesions, a femoral venous catheter was inserted without any complications. A routine ultrasound of the abdomen six hours after the trauma revealed unclear hepatic gas formation. A contrast-enhanced computer tomography $(C T)$ scan of the abdomen was performed, and the gas formation was found to be localized within the left hepatic vein. Afterwards, there was no specific treatment of the hepatic venous gas formation, as no alterations of liver function or liver enzymes were seen. The further course of the patient was uneventful regarding the gas formation in the liver, and another ultrasound two days later revealed no further gas in the liver.

Conclusions: The placement of a femoral venous catheter is a risk factor for gas formation in liver veins. No further treatment is needed in cases with stable liver function. To rule out serious pathologies, diagnostic findings (e.g., ultrasound, CT), clinical history and underlying diseases need to be analyzed carefully after the detection of intrahepatic gas formation. With contrast-enhanced $\mathrm{CT}$, the localization of the gas and its potential causes might be detectable.

Keywords: Abdominal trauma, Gas, Liver vein

\section{Background}

There are numerous causes of hepatic gas formation [1]. They range from serious pathologies, such as mesenteric infarction, liver abscess, inflammatory bowel disease, thrombosis of a hepatic artery after liver transplantation, cholecystitis and cholangitis, to incidental findings without any consequences. Furthermore, minimally invasive hepatic interventions (endoscopic retrograde cholangiopancreatography, hepatic artery embolization, tumour ablation, liver biopsy, portal vein embolization) are

\footnotetext{
* Correspondence:

${ }^{1}$ University Hospital Jena, Division of General, Visceral and Vascular Surgery,

Am Klinikum 1, 07740 Jena, Germany

Full list of author information is available at the end of the article
}

increasing in frequency, so it is important to rule out these procedures as potential causes of the gas formation in order to detect life-threatening conditions in the patient. Therefore, the patient's history and the radiological findings need to be analyzed carefully. We report here a case of hepatic gas formation after a motor vehicle crash with suspected blunt abdominal trauma and discuss the potential diagnosis.

\section{Case presentation}

A 50-year-old man was admitted to the emergency room after a car crash. At the time of admission, the patient was conscious and hemodynamically stable. Therefore, a computer tomography (CT) scan was performed for 
further diagnostics and revealed a craniocerebral injury that involved a fracture of the skull with concomitant soft tissue lesions and subarachnoidal bleeding. In addition, the patient suffered blunt thoracic trauma with hemopneumothorax due to rib fractures, which was treated with a chest tube. No obvious abdominal pathology was seen. The patient was transferred to the operating theatre for surgical revision of the soft tissue lesions. During general anesthesia, a femoral venous catheter was inserted without any procedural complications. Postoperatively, the patient was monitored in the intensive care unit. At our institution, a repeated ultrasound of the abdomen is performed six hours after the trauma to rule out free abdominal liquid or lesions of the parenchymatous organs, because it has been shown that repeated ultrasound examinations decrease the rate of false negative results and increase the sensitivity to detect intraabdominal liquid $[2,3]$. In our patient, an unclear hepatic gas formation in the liver veins was seen but still no free liquid. For further differentiation and localization of the gas formation, a contrast-enhanced CT scan of the abdomen was performed. Here, the gas formation was localized in the left hepatic vein (Fig. $1 \mathrm{a} /$ b, black arrow). In addition, the central venous catheter in the inferior vena cava was visible without hematoma or gas formation (Fig. 1 b, white arrow), and no additional abdominal pathology was noted.

There was no specific treatment administered for the hepatic venous gas formation. The further course of the patient was uneventful regarding the gas formation in the liver, and an additional ultrasound to check for further gas formation two days later revealed no more gas in the liver. No changes in liver function or liver enzymes were seen.

\section{Discussion und conclusions}

Gas formation within the hepatic veins is rarely seen in routine CT scans, and only a few cases have been reported so far. The largest published investigation of patients with gas formation in the liver vein analyzed 235 CT scans of intensive care unit patients and found that $5 \%$ of the CT scans showed gas formation in the hepatic veins [4]. All patients with gas in their hepatic veins in this study had received a femoral venous catheter. Therefore, the authors concluded that a femoral venous catheter is one of the most important risk factors for this complication. Further, they recommended performing a multiplanar reconstruction of the liver vascular structures to identify the localization of the gas formation. Portal venous gas [5, 6], pneumobilia [7] or gas in the liver artery [8] were considered as differential diagnoses and lead to further diagnostics and therapy. In postmortem studies, cardiac gas embolism, putrefaction processes, and open skull fractures due to craniocerebral injury or gunshot injury to the head were associated with gas in the hepatic veins [9-11]. In addition, gas embolism in the hepatic vein during laparoscopic liver surgery has been reported [12-14]. As interventional therapies of the liver, such as endoscopic retrograde cholangiopancreatography, hepatic artery embolization, tumour ablation, liver biopsy, and portal vein embolization, are increasing in number, postinterventional complications with gas within the liver are seen more frequently.

In this report, the further course of the patient was uneventful, and a subsequent ultrasound revealed no more gas in the liver, and no changes in liver function were detected. Most likely, the detection of hepatic venous gas formation in our patient was a coincidence related to the placement of the femoral venous catheter and the open skull fracture. This might explain why the initial CT scan was unremarkable and showed no pathology of the liver.

It has been shown that focused abdominal sonography after blunt abdominal trauma is a reliable and sensitive technique in the hands of experienced investigators $[3,15]$. In the case of negative findings, repeated examinations
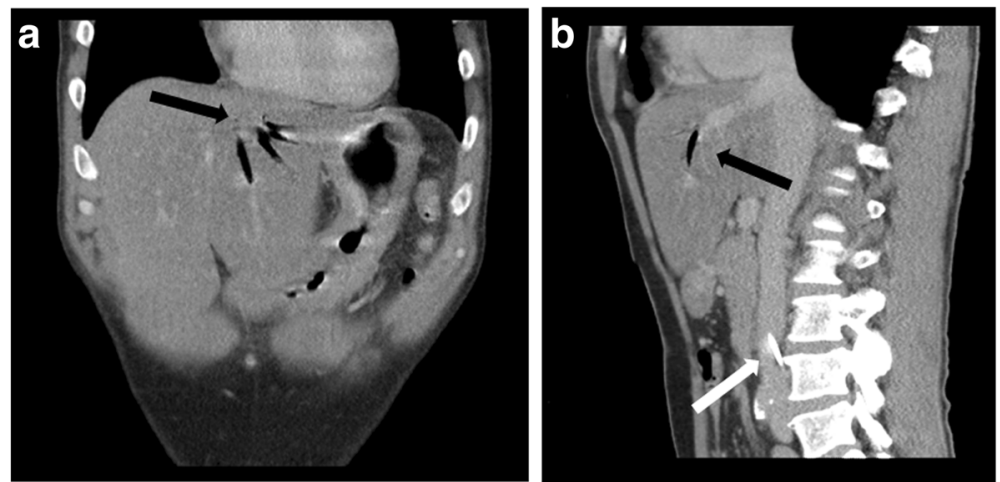

Fig. 1 Contrast-enhanced CT scan of the abdomen several hours after a car crash with suspected blunt abdominal trauma showing gas formation within the left liver vein (black arrow $\mathbf{a}, \mathbf{b}$ ). Furthermore, the central venous catheter is seen in the vena cava inferior (white arrow, b) 
may help decrease the rate of false negative results and increase the sensitivity to detect free abdominal liquid [2, 3, 15]. Intravascular abdominal gas after blunt abdominal trauma is rarely seen and is postulated to be a transient finding that can often be treated non-surgically [16, 17]. In total, posttraumatic hepatic gas formations have been reported more frequently within the portal venous system than within the hepatic venous system.

Portal venous gas in combination with pneumatosis intestinalis might be a sign of intestinal ischemia but might also occur after blunt abdominal trauma or abdominal surgery $[5,6,17,18]$. In this patient, there was no evidence of intestinal ischemia from the clinical examination or the CT scan. Pneumobilia is reported as a consequence of blunt abdominal trauma [7], but in our patient, this pathology was not supported by the localization of the gas formation. Infectious and abscessforming complications after liver transplantation [8] or liver abscess [19] with gas in the hepatic artery are rare, and they were not considered reasonable diagnoses in our patient due to the short-time follow-up. As the patients' history was uneventful until the car crash, complications of minimally invasive interventions to the liver were also not reasonable.

The causes of hepatic gas formation might range from serious pathologies to incidental, harmless findings. Therefore, it is important to analyze and clarify the underlying cause of hepatic gas formation when it is identified. Multiplanar reconstructions of the vascular structures of the liver by CT scan have been recommended as a means of identifying the exact localization of the gas formation within the liver. Depending on the diagnosis, further treatment may be necessary. Gas formation within the hepatic veins is rare and usually harmless, as in our case, without the need for medical or surgical treatment.

\section{Abbreviations}

CT: Computer tomography

\section{Acknowledgements}

Not applicable.

Funding

There was no funding for this study.

\section{Availability of data and materials}

The datasets used and/or analyzed during the current study are available from the corresponding author on reasonable request.

\section{Authors' contributions}

Study concept and design: RF, FR, HS, US. Acquisition of data: RF, FR, HS, US. Analysis and interpretation of data: RF, FR, HS, US. Drafting of manuscript: RF. Critical revision of manuscript: FR, HS, US. All authors have read and approved the final version of this manuscript.

Ethics approval and consent to participate Not applicable.
Consent for publication

The patient's spouse gave written consent to publish this case report.

Competing interests

The authors declare that they have no conflict of interest.

\section{Publisher's Note}

Springer Nature remains neutral with regard to jurisdictional claims in published maps and institutional affiliations.

\section{Author details}

${ }^{1}$ University Hospital Jena, Division of General, Visceral and Vascular Surgery, Am Klinikum 1, 07740 Jena, Germany. ${ }^{2}$ St. Vincenz Hospital, Division of General and Visceral Surgery, Am Busdorf 2, 33098 Paderborn, Germany.

Received: 8 August 2017 Accepted: 19 February 2018

Published online: 02 March 2018

\section{References}

1. Shah PA, Cunningham SC, Morgan TA, Daly BD. Hepatic gas: widening spectrum of causes detected at $C T$ and US in the interventional era. Radiographics : a review publication of the Radiological Society of North America, Inc. 2011;31(5):1403-13.

2. Hoffmann R, Nerlich M, Muggia-Sullam M, Pohlemann T, Wippermann B, Regel G, Tscherne H. Blunt abdominal trauma in cases of multiple trauma evaluated by ultrasonography: a prospective analysis of 291 patients. J Trauma. 1992;32(4):452-8.

3. Nunes LW, Simmons S, Hallowell MJ, Kinback R, Trooskin S, Kozar R. Diagnostic performance of trauma US in identifying abdominal or pelvic free fluid and serious abdominal or pelvic injury. Acad Radiol. 2001;8(2):128-36

4. Galbois A, Cazejust J, Arrive L, Boelle PY, Ait-Oufella H, Baudel JL, Alves M, Margetis D, Offenstadt G, Guidet B, et al. Femoral venous catheter: a misleading cause of gas in the liver. Crit Care Med. 2011;39(11):2447-51.

5. Khalaf N, Mittal S. Hepatic portal venous gas: an ominous sign of mesenteric ischemia. Clinical gastroenterology and hepatology : the official clinical practice journal of the American Gastroenterological Association. 2014;12(6): xxix-xx.

6. Hashimoto A, Fuke H, Shimizu A, Shiraki K. Hepatic portal venous gas caused by non-obstructive mesenteric ischemia. J Hepatol. 2002;37(6):870

7. Barnes SL, Badrudduja M, Bernard AC, Boulanger BR. Pneumobilia after blunt trauma: a self-limited condition? J Trauma. 2006;60(3):637-9.

8. Shaked A, McDiarmid SV, Harrison RE, Gelebert HA, Colonna JO 3rd, Busuttil RW. Hepatic artery thrombosis resulting in gas gangrene of the transplanted liver. Surgery. 1992;111(4):462-5.

9. Egger C, Bize P, Vaucher P, Mosimann P, Schneider B, Dominguez A, Meuli R, Mangin P, Grabherr S. Distribution of artifactual gas on postmortem multidetector computed tomography (MDCT). Int J Legal Med. 2012;126(1):3-12.

10. Jackowski C, Sonnenschein M, Thali MJ, Aghayev E, Yen K, Dirnhofer R, Vock $P$. Intrahepatic gas at postmortem computed tomography: forensic experience as a potential guide for in vivo trauma imaging. J Trauma. 2007; 62(4):979-88.

11. Sapienza D, Bottari A, Gualniera P, Asmundo A, Perri F, Gaeta M. Post mortem CT of intrahepatic gas distribution in twenty-seven victims of a flood: patterns and timing. Legal Med. 2017;29:18-21.

12. Otsuka Y, Katagiri T, Ishii J, Maeda T, Kubota Y, Tamura A, Tsuchiya M, Kaneko H. Gas embolism in laparoscopic hepatectomy: what is the optimal pneumoperitoneal pressure for laparoscopic major hepatectomy? Journal of hepato-biliary-pancreatic sciences. 2013;20(2):137-40.

13. Eiriksson K, Fors D, Rubertsson S, Arvidsson D. High intra-abdominal pressure during experimental laparoscopic liver resection reduces bleeding but increases the risk of gas embolism. Br J Surg. 2011;98(6):845-52.

14. Kawahara T, Hagiwara M, Takahashi H, Tanaka M, Imai K, Sawada J, Kunisawa T, Furukawa H. Cerebral infarction by paradoxical gas embolism during laparoscopic liver resection with injury of the hepatic vessels in a patient without a right-to-left systemic shunt. The American journal of case reports. 2017;18:687-91

15. Tsui CL, Fung HT, Chung KL, Kam CW. Focused abdominal sonography for trauma in the emergency department for blunt abdominal trauma. Int $J$ Emerg Med. 2008;1 (3):183-7. 
16. Brown MA, Hauschildt JP, Casola G, Gosink BB, Hoyt DB. Intravascular gas as an incidental finding at US after blunt abdominal trauma. Radiology. 1999; 210(2):405-8.

17. Mayet M, Hardcastle TC, Muckart DJ. Benign portal venous gas after blunt abdominal trauma. Injury Extra. 2011;42:189-91.

18. Ginesu GC, Barmina M, Cossu ML, Feo CF, Fancellu A, Addis F, Porcu A.

Conservative approach to hepatic portal venous gas: a case report. Int J Surg Case Rep. 2017;30:183-5.

19. Jun $\mathrm{CH}$, Yoon JH, Wi JW, Park SY, Lee WS, Jung SI, Park CH, Joo YE, Kim HS, Choi SK, et al. Risk factors and clinical outcomes for spontaneous rupture of pyogenic liver abscess. J Dig Dis. 2015;16(1):31-6.

Submit your next manuscript to BioMed Central and we will help you at every step:

- We accept pre-submission inquiries

- Our selector tool helps you to find the most relevant journal

- We provide round the clock customer support

- Convenient online submission

- Thorough peer review

- Inclusion in PubMed and all major indexing services

- Maximum visibility for your research

Submit your manuscript at www.biomedcentral.com/submit 